\title{
JC Virus Granule Cell Neuronopathy as AIDS-Presenting Illness
}

\author{
Simon Grandjean Lapierre, Xin Dang, Danielle Gilbert, Sylvie Lauzier, \\ Igor J. Koralnik, Louiselle LeBlanc
}

\begin{abstract}
JC virus is the etiological agent of progressive multifocal leukoencephalopathy, a white matter demyelinating disease that mostly affects immunocompromised patients. JC virus can also infect neurons and meningeal cells and cause encephalitis, meningitis and granule cell neuronopathy. We report a patient with JC virus granule cell neuronopathy, without concomitant progressive multifocal leukoencephalopathy, presenting as inaugural acquired immune deficiency syndrome-related illness. This patient's human immunodeficiency virus infection remained undiagnosed for several months after neurological symptoms onset. We review JC virus pathophysiology, clinical manifestations, treatment and prognosis, and emphasize the importance of considering human immunodeficiency virus infection and related opportunistic infections in the differential diagnosis of new-onset isolated cerebellar disease.
\end{abstract}

RÉSUMÉ: Un cas de neuropathie des cellules granulaires causé par le virus JC et relié au syndrome d'immunodéficience acquise. Le virus JC est l'agent étiologique de la leucoencéphalopathie multifocale progressive, une maladie démyélinisante de la substance blanche qui affecte surtout des patients immunodéprimés. Ce virus peut aussi infecter les cellules des neurones et des méninges et entraîner des cas d'encéphalite, de méningite et de neuropathie des cellules granulaires. Nous voulons justement faire état ici du cas d'un patient atteint de neuropathie des cellules granulaires causée par le virus JC et reliée au syndrome d'immunodéficience acquise (SIDA). À noter que ce patient n'a pas développé, de façon concomitante, la leucoencéphalopathie multifocale progressive. Dans son cas, l'infection au VIH est demeurée non diagnostiquée plusieurs mois après l'apparition des premiers symptômes neurologiques. Nous nous sommes donc penchés sur la physiopathologie du virus JC, sur ses manifestations cliniques, sur ses traitements et sur le pronostic pouvant être établi. Nous avons aussi voulu souligner l'importance de considérer l'infection au VIH et d'autres infections opportunistes y étant reliées à la lumière du diagnostic différentiel d'une maladie cérébelleuse isolée nouvellement déclarée.

Keywords: HIV, Neuroimaging, JC virus, Granule cell neuronopathy, Demyelination

doi:10.1017/cjn.2018.28

Can J Neurol Sci. 2018; 45: 466-469

A 51-year-old woman presented with progressive isolated cerebellar symptoms. She had no history of neurological disease, but had undergone splenectomy at the age of 24 years for refractory lymphopenia of unknown etiology. She had a 1-month history of progressive gait instability and decreased right-sided coordination with truncal ataxia and right hand dysmetria. Brain computerized tomography and MRI failed to show any abnormality.

Four months after symptoms onset, she was unable to walk alone, her speech became slurred and she developed severe postural ataxia, bilateral gaze-evoked horizontal nystagmus with saccadic pursuit, appendicular dysmetria, dysarthria and brisk and pendular deep tendon reflexes bilaterally. Cognitive, motor and sensory functions were spared. MRI showed new-onset non-enhancing cerebellar vermis atrophy without any white matter signal anomaly. CSF analysis revealed 1 white blood cell $/ \mu \mathrm{l}$, a protein count of $0.29 \mathrm{~g} / \mathrm{L}$ and a normal glucose level. CSF cultures, syphilis VDRL, HSV 1 and 2, and cytomegalovirus PCR were all negative. Work-up for metabolic, autoimmune and paraneoplastic conditions including cerebellar-specific auto-antibodies Anti-Hu, Anti-Ri and Anti-Yo was unrevealing.

Human immunodeficiency virus-1 (HIV-1) was diagnosed 5 months after symptoms onset. Baseline plasma viral load was 19,530 copies/ml, CD4 + lymphocyte count was 111 cells/ $\mu$ l and virus was pan-sensitive to antiretroviral therapy (ART).
Considering newly recognized immunosuppression, CSF analysis was repeated and an extended infectious work-up was negative, except for JC virus (JCV) quantitative PCR assay of 60,000 copies/ml and HIV CSF viral load of 3521 copies/ml. JC virus DNA sequencing of the VP1 sub-unit capsid protein gene revealed a co-infection with the previously described $\mathrm{JCV}_{\mathrm{GCN} 1}$ variant and the novel variant $\mathrm{JCV}_{\mathrm{GCN} 8}$ (Figure 1). In the absence of clinical or radiological signs compatible with PML, the patient was diagnosed with isolated JCV granule cell neuronopathy (JCV GCN).

From the Infectious Diseases and Microbiology Department, Centre Hospitalier de l'Université de Montréal, Montréal, Québec, Canada (SGL); Infectious Diseases, Immunology and Microbiology Department, Université de Montréal, Montréal, Québec, Canada (SGL, LL); Department of Neurological Sciences, Rush University Medical Center, Chicago, Illinios (XD, IJK); Neurology Department, Hôpital du Sacré Coeur de Montréal, Montréal, Quebec Canada (SL); Radiology Department, Hôpital du Sacré Coeur de Montréal, Montréal, Quebec Canada (DG); Infectious Diseases and

Microbiology Department, Hôpital du Sacré Coeur de Montréal, Montréal, Quebec Canada (LL).

Received January 16, 2018. Final Revisions Submitted February 28, 2018. Date of ACceptance March 2, 2018.

Correspondence to: S. Grandjean Lapierre, Infectious Diseases and Medical Microbiology, Universitair Medisch Centrum Groningen, Montreal, QC, Canada 9700 RB. Email: simon.grandjean.lapierre@umontreal.ca 


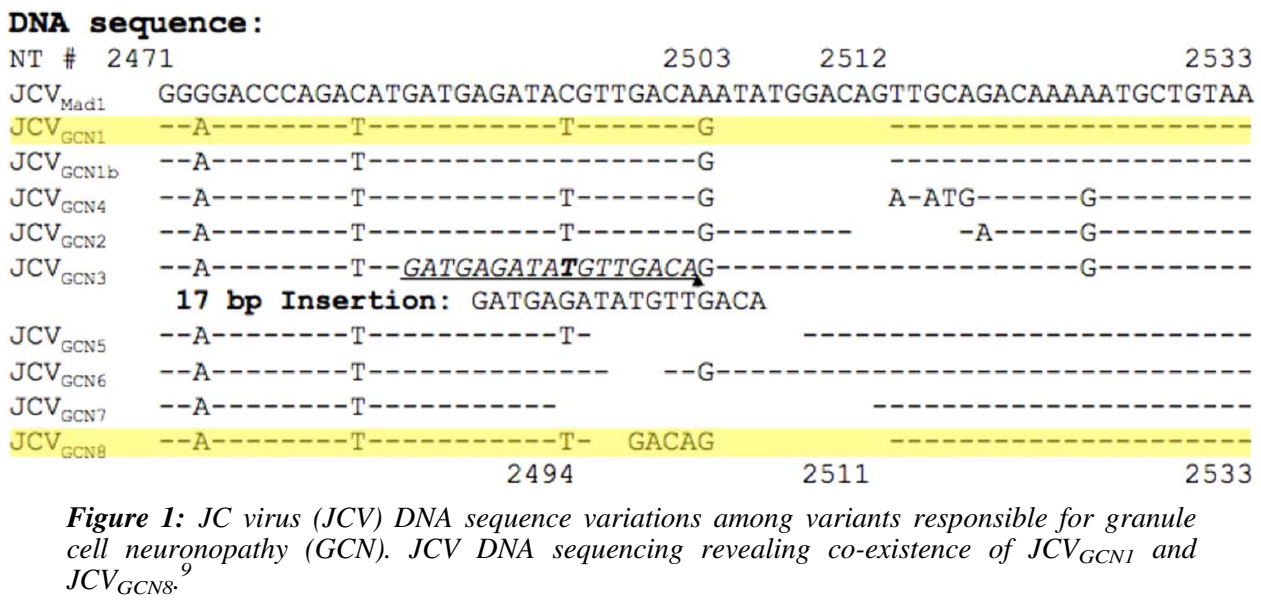

Central nervous system (CNS)-penetrating ART including abacavir/lamivudine and lopinavir/ritonavir was initiated and eventually switched to darunavir/ritonavir. Despite HIV-1 viral load becoming undetectable after 8 weeks and CD4+ lymphocyte count rising to $222 \mathrm{cells} / \mu \mathrm{l}$, she experienced relentless neurological worsening and cerebellar atrophy (Figure 2). Six months after ART initiation, CSF HIV viral load was undetectable, but JCV remained elevated at 30,000 copies $/ \mathrm{ml}$. The absence of gadolinium enhancement or mass effect on MRI and weak JC-virus-specific CD4 + and CD8 + T-cell responses argued against PML immune reconstitution syndrome (PML-IRIS). To investigate this possibility, proton magnetic resonance spectroscopy was proposed, but the patient declined further investigation.

Three years after initial presentation, cerebellar symptoms finally stabilized, but the patient showed no sign of neurological recovery. This is the first reported case of isolated JCV GCN, without clinical or radiological evidence of PML, manifesting as an AIDS-presenting illness in a previously undiagnosed HIV-infected individual.

PML was first described in 1958 and JCV was identified as its causative agent in 1971. JC virus is recognized as the causative agent of multiple neurological syndromes. ${ }^{1}$ Two cases of JCV encephalitis, one case of JCV meningitis and an increasing number of JCV granule cell neuropathy and PML-IRIS have now been reported. ${ }^{2,3}$ Initially mainly reported in the context of hematological malignancies, the HIV epidemic and use of chemotherapy and immunomodulatory drugs including natalizumab and rituximab have significantly modified the epidemiology of JCV-associated CNS diseases. ${ }^{4,5}$

JC virus is believed to initially infect children through the upper respiratory tract or the urine-oral route before establishing latency in kidney, bone marrow and spleen. In immunocompromised hosts, JCV can reactivate, spread to the CNS and enter permissive host cells, a process facilitated by serotonin receptors. Lytic infection of oligodendrocytes and astrocytes target cells results in multifocal white matter and white-gray matter junction demyelination, a disease known as classical PML. VP1 capsid protein is thought to play a crucial role in pathophysiology, immune response mediation and cell entry. Although capsid proteins coding regions express high genetic stability, mutations and subsequent changes in capsid structure may alter target cell specificity and clinical presentation. ${ }^{6}$ Multiple JCV variants with mutations in the VP1 coding region were described and linked to lytic infection of cerebellar granule cell neurons and cerebellar atrophy. Infection with one of these mutants results in JCV GCN, a rare neurologic condition that can present with or without classical PML. JC virus GCN typically occurs in the same immunocompromised populations as classical PML. Specific clinical features are those of a subacute progressive cerebellar syndrome associated with cerebellar atrophy on brain imaging. ${ }^{7}$ Combined with a positive CSF JCV PCR, these clinical features yield a virological diagnosis of JCV GCN. ${ }^{8,9}$ A histological diagnosis requires hypochromatic, enlarged granule cell neurons expressing JCV proteins on cerebellum biopsy. As it is the case in HIV-negative patients, JCV GCN may occur with or without classical PML. Probable JCV GCN was previously described in a newly diagnosed HIV patient with cerebellar deficits, but JCV PCR testing on CSF remained negative and no biopsy was performed. ${ }^{10}$

PML 1-year survival increased from a few months 20 years ago to 50\%-60\% in HIV-positive patients with the advent of ART. As no specific treatment showed efficacy against JCV, no further progress was made since. Serotonin receptors targeting drugs chlorpromazine and mirtazapine were inconsistently reported as effective. DNA replication inhibitors cytarabine and cidofovir showed no benefit in HIV patients. Despite in vitro activity against JCV, a trial with mefloquine was terminated after interim analysis suggested that data were unlikely to show a significant difference between groups. In HIV-negative cases, discontinuation of immunosuppressive agents is essential. In HIV-positive cases, factors associated with favorable outcome are CD4 count greater than 100 cells $/ \mu \mathrm{l}, \mathrm{CSF}$ inflammatory response and early diagnosis and ART initiation. ${ }^{5}$

This is the first reported confirmed JCV GCN case presenting as inaugural HIV/AIDS-related illness. Isolated cerebellar disease caused by JCV GCN should be considered as an HIV/AIDS opportunistic infection. Isolated cerebellar disease should evoke the possibility of undiagnosed HIV infection and trigger subsequent testing since early diagnosis, and rapid reversal of immunosuppression with ART only can prevent progression to irreversible disease. Furthermore, CSF JCV testing should always be performed in immunocompromised patients presenting with isolated cerebellar disease or atrophy regardless of their HIV status. 

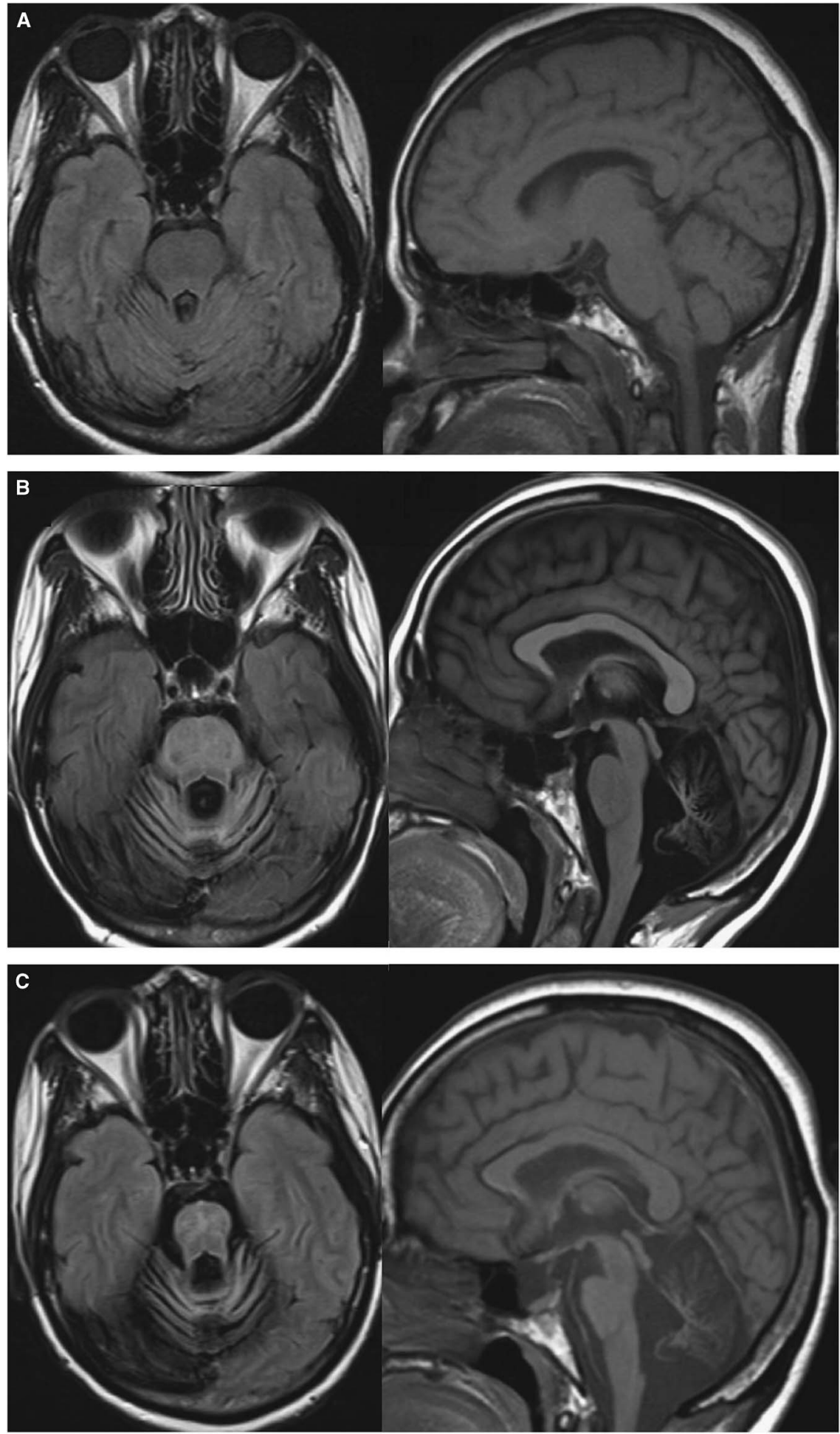

Figure 2: Evolution of MRI abnormalities at (A) 1 month, (B) 10 months and (C) 22 months after symptoms onset. Axial FLAIR sequences showed marked posterior fossa atrophy without signal abnormality (left) and Sagittal T1 sequences showed progressive pontocerebellar and pons atrophy (right).

\section{ACKNOWLEDGMENT}

This study was funded in part by NIH grant R01 NS047029 and R01 NS074995 to IJK. The authors have no conflicts of interest to declare.

\section{DISCLOSURES}

SGL, XD, DG, SL and LL have nothing to disclose. IJK has the following disclosure: NIH Grant R01 NS047029 and R01 NS074995. 


\section{Statement of Authorship}

SGL carried out infectious disease clinical care, chart review, data gathering and manuscript writing, and is the corresponding author; DG performed diagnostic radiology examination interpretation and follow-up; SL performed neurology clinical care; XD and IJK carried out CSF molecular analysis, viral genome sequencing and lymphocyte activity assessment; LL carried out infectious disease clinical care, long-term patient follow-up and manuscript writing.

\section{REFERENCES}

1. Miskin DP, Koralnik IJ. Novel syndromes associated with JC virus infection of neurons and meningeal cells: no longer a gray area. Curr Opin Neurol. 2015;28(3):288-94.

2. Agnihotri SP, Wuthrich C, Dang X, et al. A fatal case of JC virus meningitis presenting with hydrocephalus in a human immunodeficiency virus-seronegative patient. Ann Neurol. 2014; 76(1):140-7.

3. Bialasiewicz S, Hart G, Oliver K, et al. A difficult decision: atypical JC polyomavirus encephalopathy in a kidney transplant recipient. Transplantation. 2017;101(6):1461-7.
4. Bloomgren G, Richman S, Hotermans C, et al. Risk of natalizumabassociated progressive multifocal leukoencephalopathy. N Engl J Med. 2012;366(20):1870-80.

5. Casado JL, Corral I, Garcia J, et al. Continued declining incidence and improved survival of progressive multifocal leukoencephalopathy in HIV/AIDS patients in the current era. Eur J Clin Microbiol Infect Dis. 2014;33(2):179-87.

6. Gorelik L, Reid C, Testa M, et al. Progressive multifocal leukoencephalopathy (PML) development is associated with mutations in JC virus capsid protein VP1 that change its receptor specificity. J Infect Dis. 2011;204(1):103-14.

7. Koralnik IJ, Wuthrich C, Dang X, et al. JC virus granule cell neuronopathy: a novel clinical syndrome distinct from progressive multifocal leukoencephalopathy. Ann Neurol. 2005; 57(4):576-80

8. Dang X, Vidal JE, Oliveira AC, et al. JC virus granule cell neuronopathy is associated with VP1 C terminus mutants. J Gen Virol. 2012;93(Pt 1):175-83.

9. Agnihotri SP, Dang X, Carter JL, et al. JCV GCN in a natalizumabtreated MS patient is associated with mutations of the VP1 capsid gene. Neurology. 2014;83(8):727-32.

10. Henry C, Jouan F, De Broucker T. JC virus granule cell neuronopathy: a cause of infectious cerebellar degeneration. J Neurol Sci. 2015;354(1-2):86-90. 